Estudios Constitucionales, Año 12, No 2, 2014, pp. 29-54.

ISSN 07180195

Centro de Estudios Constitucionales de Chile Universidad de Talca

"Poder judicial y constitucionalismo democrático:

la necesidad de una teoría de la decisión judicial para preservar la autonomía del Derecho"

Lenio Luiz Streck

\title{
PODER JUDICIAL Y \\ CONSTITUCIONALISMO DEMOCRÁTICO: \\ LA NECESIDAD DE UNA TEORÍA DE LA DECISIÓN JUDICIAL PARA PRESERVAR LA AUTONOMÍA DEL DERECHO*
}

JUDICIARY AND DEMOCRATIC CONSTITUTIONALISM: THE NEED FOR A

THEORY OF JUDICIAL DECISION TO PRESERVE THE AUTONOMY OF LAW

\author{
LENIO LUIZ STRECK ${ }^{* *}$ \\ Universidad de Vale do Rio dos Sinos \\ lenios@globo.com
}

RESUMEN: El constitucionalismo democrático proporciona una profunda transformación en el Derecho, que pasa a afirmar su autonomía. Juntamente con esto, hay un incremento en la actuación del Judicial, que, mayoritariamente comprendida como dirigida a la concretización de derechos, acaba siendo concebida bajo un doble punto de vista: o como judicialización de la politica o como activismo judicial. Ante este escenario, surge la pregunta: ¿Es necesario el activismo judicial para concretar derechos? El presente artículo pretende enfrentar los problemas por los que pasa la teoría del derecho contemporánea, que, carente de una teoría de la decisión judicial, acaba apostando en la discrecionalidadlelasticidad interpretativa para aplicación del derecho, lo que, a la luz de la teoria integrativa de Dworkin y de la hermenéutica filosófica de Gadamer, constituye un serio problema democrático.

ABSTRACT: The democratic constitutionalism provides a profound transformation in the law, which happens to assert their autonomy. Along with this, there is an increase in the performance of the judiciary, which, largely understood as aimed at the realization of rights, just being conceived under a double point of view or judicialization of politics or judicial activism. Considering this scenario, the question arises: is it necessary judicial activism to concretize rights? This article aims to face the problems in contemporary legal theory, which, without a theory of judicial decision, bets on the discretion/flexibility interpretative to applicate the law, which, in light of the theory Dworkin integrative and philosophical hermeneutics of Gadamer, is a seriously democratic problem.

PalabRas CLAVE: Judicial, Discrecionalidad, Activismo, Judicialización de la política.

KEY WORDS: Judicial, Discretion, Activism, Judicialization policy.

\footnotetext{
* Trabajo recibido el 4 de enero de 2014 y aceptado el 6 de agosto de 2014.

** Doctor en Derecho (UFSC); Posdoctor en Derecho (Universidad de Lisboa); Profesor Titular de la UNISINOS-RS; Procurador de Justicia-RS-BRASIL. Ha publicado en español los libros siguientes: Verdad y Consenso (BdeF, 2012), Hermenéutica y Decisión Judicial (Javeriana, 2013), y otros.
} 


\section{CONSIDERACIONES PRELIMINARES - LA REVOLUCIÓN COPERNICANA DEL DERECHO OPERADA POR EL NUEVO CONSTITUCIONALISMO}

En estos tiempos pospositivistas (con todos los problemas que este término acarrea), cada vez más hay que discutir las condiciones de posibilidad de la validez del derecho en un contexto en el que los discursos predatorios de esa validez, advenidos del campo de la política, de la economía y de la moral, buscan debilitarla. Se trata, en fin, de discutir el papel del derecho en la democracia, sus límites y su fuerza normativa.

En otras palabras, en este periodo de la historia, no puede considerarse válido un derecho que no sea legitimado por el sello indeleble de la democracia. En este sentido, pienso que el derecho debe ser preservado en aquello que es su principal conquista a partir de la segunda posguerra: su grado de autonomía.

El nuevo papel del derecho está bien representado en aquello que Jorge Miranda llamó "Revolución Copernicana del Derecho Público", o sea, el nuevo lugar ocupado por las Constituciones de la segunda Posguerra y el igualmente nuevo papel ejercido por los Tribunales Constitucionales, principalmente en el campo de Europa Continental.

En este sentido, es importante recordar que es en ese contexto de afirmación de las Constituciones y del papel de la jurisdicción constitucional que teóricos de los más variados campos de las ciencias sociales -sobre todo de los sectores vinculados a la sociología, a la ciencia política y al derecho- empezaron a tratar de fenómenos como la judicialización de la política y el activismo judicial. Ambos temas pasan por el enfrentamiento del problema de la interpretación del derecho y del tipo de argumento que puede, legítimamente, componer una decisión judicial.

En otras palabras: ¿Cuáles son las condiciones de posibilidad del argumento jurídico decisorio? ¿Bajo qué circunstancias es posible afirmar que el tribunal, en el momento de la interpretación de la constitución, no está sustituyendo al legislador y profiriendo argumentos de política o de moral? En este punto es importante mencionar estudios como The global expansion of Judicial Power: the judicialization of politics (Chester Neal Tate y Torbjörn Vallinder) ${ }^{1}$, On law, politics \& judicialization (Martin Shapiro, Martin y Alec Stone Sweet) ${ }^{2}$, Towards juristocracy: the origins and consequences of the new constitutionalism

1 Tate, Neal C.; Vallinder, Torbjörn (1995).

2 Shapiro, Martin; SweEt, Alec Stone (2002). 
$\left(\right.$ Ran Hirschl) ${ }^{3}$. En otra perspectiva, pero apuntando también a la incisividad del Poder Judicial en la conducción de la vida política, está el artículo Tomada de Decisóes em uma democracia: a Suprema Corte como uma entidade formuladora de politicas nacionais (Robert A. Dahl) ${ }^{4}$.

Ese es el gran dilema contemporáneo. Superadas las formas de positivismo exegético racionalista (formas exegéticas), los juristas todavía no consiguieron construir las condiciones para el control de las posturas voluntaristas (que, es importante registrar, por apostar en la discrecionalidad de los jueces, no dejan de ser también positivistas). Si antes el intérprete estaba sometido a una estructura preestablecida, ya a partir del siglo XX, el dilema pasó a ser: ¿cómo establecer controles a la interpretación del derecho y evitar que los jueces se apoderen de la legislación democráticamente construida?

Uno de los síntomas de ese problema reside en el crecimiento -sobre todo en países como Brasil- del fenómeno del "activismo judicial", factor de debilitación del grado de autonomía alcanzado por el derecho en este nuevo paradigma.

\section{LA CONSTITUCIÓN Y LA EXIGENCIA DE NUEVOS PARADIGMAS INTERPRETATIVOS.}

\section{LAS RECEPCIONES TEÓRICAS EQUIVOCADAS}

Una Constitución nueva exige, por lo tanto, nuevos modos de análisis: como mínimo, una nueva teoría de las fuentes, una nueva teoría de la norma, una nueva teoría hermenéutica. La pregunta que se hacía era: ¿Cómo podríamos mirar lo nuevo con los ojos de lo nuevo? Al final, nuestra tradición jurídica estaba asentada sobre un modelo liberal individualista (que opera con los conceptos oriundos de las experiencias de la formación del derecho privado francés y alemán), donde no había lugar para derechos de segunda y tercera dimensiones. Además, no había una teoría constitucional adecuada a las demandas de un nuevo paradigma jurídico.

Esas carencias tiraron a los juristas brasileños a los brazos de las teorías alienígenas. Consecuentemente, las recepciones de esas teorías fueron realizadas, muchas veces, de modo acrítico, siendo la apuesta en el protagonismo de los jueces el punto común de la mayor parte de las posturas. Como efecto, hubo un real "incentivo" doctrinario a partir de tres principales posturas o teorías: la jurisprudencia de los valores, el realismo norteamericano (con énfasis en el activismo judicial) y la teoría de la argumentación de Robert Alexy. Veamos cada una de

3 Hirschl, Ran (2009).

4 DAHL, Robert (2009), pp. 25-43. 
esas recepciones equivocadas siendo que, por la forma como son trabajadas en Brasil, la jurisprudencia de los valores y la teoría de la argumentación de Robert Alexy serán analizadas en conjunto.

\section{Jurisprudencia de los Valores y Teoría de la Argumentación Jurídica: los equivocos de una recepción}

Como se sabe, en el caso alemán, la jurisprudencia de los valores sirvió para ecualizar la tensión producida después de la otorgación de la Ley Fundamental (Grundgesetz) por los aliados, en 1949. Con efecto, en los años que sucedieron a la consagración de la ley fundamental, hubo un esfuerzo considerable por parte del Tribunal Constitucional Federal de Alemania (Bundesverfassungsgericht) para legitimar una Carta que no había sido constituida por la amplia participación del pueblo alemán. De ahí la afirmación de un jus distinto de la lex, o sea, la invocación de argumentos que permitiesen al Tribunal recurrir a criterios decisorios que se encontraban fuera de la estructura rígida de la legalidad. La referencia a valores aparece, así, como mecanismo de "apertura" de una legalidad extremamente cerrada.

En este sentido, no podemos olvidarnos de que la tesis de la jurisprudencia de los valores es, hasta hoy, de cierto modo, preponderante en aquel tribunal, circunstancia que ha provocado históricamente fuertes críticas en el plano de la teoría constitucional al modus interventivo del tribunal alemán ${ }^{5}$. Es importante señalar, sin embargo, que la referida tensión efectivamente tuvo, a partir de la segunda posguerra, un papel fundamental en la construcción de la teoría constitucional contemporánea, por ejemplo, en Portugal, España y Brasil.

Sin embargo -y aquí se debe hacer la crítica al equívoco en el modo como la tesis fue recibida- los juristas brasileños no se fijaron en las distintas realidades (Brasil y Alemania). En el caso específico de Brasil, donde, históricamente aun la legalidad burguesa ha sido difícil de realizar, la gran lucha ha sido la de establecer las condiciones para el fortalecimiento de un espacio democrático de edificación de la legalidad, plasmado en el texto constitucional.

De la jurisprudencia de los valores los teóricos brasileños tomaron prestado la tesis principal, la de que la Constitución es un orden concreto de valores, siendo el papel de los intérpretes el de encontrar y revelar estos intereses o valores. El modo más específico de implementación fue la teoría de la argumentación de Robert Alexy, que, no obstante, recibió una lectura superficial por una parte considerable de la doctrina y de los Tribunales.

5 Cf. Habermas (1992). 
El Derecho Constitucional, así, fue tomado por las teorías de la argumentación jurídica, siendo raro encontrar constitucionalistas que no se rindan a la distinción estructural regla-principio y a la ponderación (Alexy). A partir de ese equívoco, son desarrolladas/seguidas diversas teorías/tesis a veces incompatibles entre sí ${ }^{6}$. En la mayor parte de las veces, los adeptos de la ponderación no tienen en cuenta la relevante circunstancia de que es imposible hacer una ponderación que resuelva directamente el caso. La ponderación -en los términos propalados por su creador, Robert Alexy- no es una operación en la que se ponen los dos principios en una balanza y se apunta a aquél que "pesa más" (sic), algo como "entre dos principios que coliden, el intérprete elige uno" (sic). En este sentido hay que hacer justicia a Alexy: su tesis sobre la ponderación no envuelve esa "elección directa".

Importante añadir que en Brasil, los tribunales, en el uso sin criterios de la teoría alexiana, transformaron la regla de la ponderación en un principio. En efecto, si en la construcción propuesta por Alexy la ponderación conduce a la formación de una regla -que será aplicada al caso por subsunción-, los tribunales brasileños utilizan ese concepto como si fuese un enunciado performativo (performative utterance) ${ }^{7}$, una especie de coartada teórica capaz de fundamentar los posicionamientos más diversos. Ese tratamiento equivocado -que entiende la ponderación como un principio- queda evidente a partir de una simple investigación en los tribunales brasileños ${ }^{8}$. Es de consignarse, por fin, que ese uso de la ponderación como un "verdadero" principio, resulta de un fenómeno muy peculiar a la realidad brasileña que vengo denominando panprincipiologismo. En líneas generales, el panprincipiologismo es un subproducto del constitucionalismo contemporáneo que acaba por debilitar las efectivas conquistas que formaron el caldo de cultivo que posibilitó la consagración de la Constitución brasileña de 1988. Ese panprincipiologismo hace que -con el pretexto de estar aplicándose

6 Con relación al tema, es importante señalar el profundo estado de embarazo teórico en el que se encuentran encauzadas algunas posturas teóricas brasileñas. En efecto, hay varios constitucionalistas proponiendo que, además de la ponderación de principios, debe existir también una ponderación entre reglas (sic). Lo que llama más la atención en una propuesta como esta es el hecho de que la ponderación es uno de los factores centrales que marcan la distinción entre reglas y principios de Robert Alexy (principios se aplican por ponderación y reglas por subsunción). Más aún: si la ponderación es el procedimiento del cual el resultado será una regla posteriormente subsumida al caso concreto, ¿qué tenemos como resultado de la "ponderación de reglas"? ¿Una "regla" de la regla? ¿Cómo queda, por lo tanto, en términos prácticos, la distinción entre reglas y principios?

7 Enunciado performativo significa uno de los tipos posibles de enunciados descritos por John Langshaw Austin, filósofo de lenguaje, en su teoría de los actos de habla. Austin llama "enunciado performativo" al que no se limita a describir un hecho, sino que cambia el hecho que describe. Véase Austin, (1998).

8 En el caso específico del STF, vale recordar la ADPF No 130/DF, del 2009. 
principios constitucionales- haya una proliferación incontrolada de enunciados para resolver determinados problemas concretos, muchas veces al albedrío de la propia legalidad constitucional.

Un ejemplo ilustrativo de ese tipo de mezcla teórica (Teoría de la Argumentación y Jurisprudencia de los Valores) puede encontrarse en el juicio del Habeas Corpus No 82424, el 17/09/2003, que quedó conocido como caso Ellwanger9. Veamos, en líneas generales, el caso presentado: en este juicio, el STF negó pedido de declaración de la extinción de la punibilidad en favor de Siegfried Ellwanger, acusado de crimen de discriminación y prejuicio contra los judíos. Ellwanger era responsable por la edición, distribución y venta de libros antisemitas de su propia autoría (Holocausto: Judeu ou Alemão? -Nos bastidores da mentira do século) y de otros autores nacionales (e. g., Brasil, Colônia de Banqueiros, de Gustavo Barroso) y extranjeros (e. g., O Judeu Internacional, de Henry Ford). La conducta de Ellwanger estaba tipificada criminalmente en el artículo 20 de la Ley No $7.716 / 89$, cuya pena era de dos a cinco años. Lo absolvieron en primer grado, y condenado en apelación, por el Tribunal de Justicia del Estado de Rio Grande do Sul. Ante el STF, la defensa sostuvo que el hecho imputado en contra del acusado prescribió, una vez que la discriminación contra judíos -al contrario de la discriminación de color- no sería protegida por la imprescriptibilidad constitucional del crimen de racismo (CF, artículo 50, XLII).

El Relator, Min. Moreira Alves, votó por la anuencia del Habeas Corpus, sosteniendo que los judíos no podrían ser víctimas de racismo, por no constituir una raza. Basó su voto (constitucionalmente inadecuado) en argumentos de política, principalmente en el hecho de que la Asamblea Constituyente había pretendido hacer imprescriptible solamente el racismo practicado contra negros.

Le correspondió al Min. Maurício Corrêa inaugurar la divergencia que saldría vencedora, señalando lo obvio: el nazismo que permeaba las obras publicadas por Ellwanger estaba fundado esencialmente en una superioridad de raza. Durante el nazismo, el pueblo judío pasó a ser tratado como subraza, y eran estas las opiniones que Ellwanger profesaba por aquí. Así, casi sin querer, el Min. Corrêa recolocó la cuestión en su debido lugar: el criterio de racismo no puede fundarse solamente en un concepto lexicográfico de raza, y la raza, para fines de protección jurídica, no se limita a una semejanza de características físicas, como el color de la piel. Aunque el Ministro no haya fundamentado de esa forma, se trata de una contextualización de

9 Disponible en: http://redir.stf.jus.br/paginadorpub/paginador.jsp?docTP=AC\&docID=79052. Acceso el: 6.07.2013. 
la tradición: la historia del siglo XX -con la persecución antisemita y el holocaustoimporta en ese análisis. Y, añado, rescata los argumentos de principio, una vez que la erradicación de las discriminaciones y prejuicios es un objetivo de la República (artículo 3o, IV, de la CF), que tienen carácter deontológico.

Sin embargo, parte del Tribunal entendió que se estaba ante una colisión de principios constitucionales. Principios estos que, a su vez, se asentaban sobre valores contradictorios entre sí. En este sentido, el Min. Carlos Ayres Britto, tras ver en el caso una "contradicción entre principios jurídicos", con "modelos normativo principiológicos en estado de fricción y que llegan a derivar hacia una forma de exclusión recíproca", entendió, por juicio de "proporcionalidad", que los hechos atribuidos a Ellwanger eran penalmente atípicos, frente a la libertad de expresión. El Min. Marco Aurélio de Mello igualmente puso la libertad de expresión y la prohibición al racismo en la balanza, y, al hacer la ponderación de los valores en juego (incluso con cita expresa de Alexy y referencia al caso Lüth, juzgado por el Tribunal Constitucional de Alemania en 1958 y visto como pionero en la ponderación de principios), concluyó por la primacía de la libertad.

De todo modo, hay que señalar que aunque ha sido objeto de innúmeros debates y ha rendido una larga discusión en la Suprema Corte (el acórdão ${ }^{10}$ del Tribunal tiene no menos que 488 páginas), la solución de la controversia era en verdad vergonzosamente simple. No había nada a ponderar, por una simple razón: la libertad de manifestación de pensamiento simplemente no abarca la libertad de manifestar un pensamiento racista. Y racismo es crimen. Imprescriptible. En este sentido, el voto del Min. Celso de Mello. En línea similar, el Min. Gilmar Mendes recordó que las sociedades democráticas no confieren derechos de expresión a los discursos de odio (hate speeches), por la simple razón de que dichos discursos comprometen la propia democracia.

Como ya ha sido adelantado, el Habeas Corpus acabó negado ${ }^{11}$. Sin embargo, los votos vencidos, basados o en argumentos de política o en juicios de ponderación bien demuestran los peligros que se corre con la teoría de la argumentación alexyana a la brasileña (que desconsidera los procedimientos formales establecidos por Alexy y termina por mezclar la ponderación alexyana con el modelo interpretativo propio de la llamada jurisprudencia de los valores). Dicho de otro

10 N.T.: Acórdão es el nombre dado en Brasil para la decisión de un órgano judicial de segunda instancia, que es compuesto por los votos de más de un juez.

11 Además de los ya mencionados Ministros Maurício Corrêa, Celso de Melo y Gilmar Mendes, también votaron por la denegación los Ministros Carlos Velloso, Nelson Jobim, Ellen Gracie, Cezar Peluso y Sepúlveda Pertence. 
modo: el recurso al relativismo ponderativo obscurece el valor de la tradición como guía de la interpretación, es decir, la ponderación acaba siendo una puerta abierta a la discrecionalidad.

\section{El activismo judicial: un ejemplo de cómo la discusión viene siendo equivocadamente hecha en Brasil}

De modo semejante, también el término activismo judicial viene siendo empleado en Brasil de un modo tábula rasa. Nótese: en los Estados Unidos $-\mathrm{y}$ esta es/fue la tercera recepción equivocada-, la discusión sobre el gobierno de los jueces y sobre el activismo judicial acumula más de doscientos años de historia. No puede olvidarse, por otro lado, que el activismo judicial en los Estados Unidos fue hecho al revés en un primer momento (de modo que no puede considerarse que el activismo sea siempre algo positivo). El típico caso de un activismo al revés fue la postura de la Suprema Corte estadounidense con relación al new deal, que, aferrada a los postulados de un liberalismo económico del tipo laissez faire, borraba, por inconstitucionalidad, las medidas intervencionistas establecidas por el gobierno de Roosevelt ${ }^{12}$. Las actitudes intervencionistas a favor de los derechos humanos fundamentales ocurren en un contexto que dependía mucho más de la acción individual de una mayoría establecida, que del resultado de un imaginario propiamente activista. El caso de la Corte Warren, por ejemplo, fue resultante de la concepción personal de cierto número de jueces y no el resultado de un sentimiento constitucional acerca de esta problemática.

Ya en Brasil ese tema toma aires dramáticos. Basta recordar, en este sentido, que activismo judicial aparece como un principio en el anteproyecto del Código Brasileño de Proceso Colectivo (artículo 2o, letra i). Por cierto, tal proyecto de ley aún no ha sido analizado por el Poder Legislativo, pero la simple mención al activismo judicial como un "principio orientador" (sic) del proceso colectivo brasileño, ya da cuenta del estado de profundo impasse teórico que impera en la doctrina.

Un buen ejemplo del tipo corriente de activismo judicial que permea el imaginario de los juristas brasileños puede ser extraído de la cuestión llevada a juicio en la Argüição de Descumprimento de Preceito (Argumentación de Descumplimiento de Precepto Fundamental) ${ }^{13}$ (ADPF) No 178. En efecto, tal medida fue interpuesta

\footnotetext{
12 Wolfe (1994).

13 En líneas generales, es posible afirmar que la ADPF es una medida similar al Recurso de Amparo o Recurso Constitucional (Verfassungsbeschwerde) del derecho alemán o del Recurso de Amparo español y
} 
en el 2009 por el Ministerio Público Federal, objetivando el reconocimiento de unión estable entre personas del mismo sexo y la garantía de los mismos derechos reconocidos a las uniones entre heterosexuales. La acción pretendía, inicialmente, que fuese reconocida la supuesta omisión del Poder Legislativo en reglamentar los derechos de las parejas homosexuales, aunque la propia Constitución, en su artículo $226, \$ 3^{\circ}$, apunta hacia otra dirección, al afirmar que "para efecto de la protección del Estado, es reconocida la unión estable entre el hombre y la mujer como entidad familiar, debiendo la ley facilitar su conversión en casamiento". Denegada por orden judicial provisional, la petición fue presentada una vez más, ahora buscando una interpretación conforme la Constitución (verfassungskonforme Auslegung) del artículo 1.723 del Código Civili ${ }^{14}$, en el sentido de ofrecer protección integral a las uniones homoafectivas.

La perplejidad que surge se debe a la siguiente cuestión: ¿de qué modo podría haber la referida omisión si la propia Constitución determina que es deber del Estado proteger la unión entre el hombre y la mujer? ¿Dónde estaría la omisión, ya que es un comando constitucional que determina que la acción del Estado sea en el sentido de proteger la unión entre hombre y mujer? Nótese: no podemos hablar en jerarquía entre normas constitucionales, caso contrario, estaríamos aceptando la tesis de Otto Bachof respecto de la posibilidad de existencia de normas constitucionales inconstitucionales. Lo más increíble es que la referida ADPF (Acción de Descumplimiento de Precepto Fundamental) también pretende anular las varias decisiones que cumplieron literalmente el referido comando constitucional. Se trata, pues, de un híper activismo.

De plano, salta a la vista la siguiente cuestión: la concreción de una medida de ese juez importaría convertir el Tribunal en un órgano con poderes permanentes de alteración de la Constitución, afirmando una especie caduca de mutación cons-

mexicano. Sin embargo, la Ley No 9882/1999 que reglamentó lo dispuesto en el $\$ 1^{\circ}$ del artículo 102 de la CF, terminó por restringir -de manera inconstitucional- la relación de legitimados para proponer ese importante instrumento de concretización de los derechos fundamentales. La importancia de ese mecanismo para la interpretación de la Constitución puede ser comprobada por lo que viene siendo debatido en la ADPF No 54 (que discute la constitucionalidad de la criminalización del aborto en los casos de anencefalia); ADPF No 130 (cuyo problema central giró alrededor de la libertad de prensa y de la (im)posibilidad de censura previa) y la ADPF No 153 (que versaba sobre la posibilidad de persecución y punición de los crímenes de tortura ocurridos durante el régimen militar). Es importante destacar que la ADPF No 130 fue juzgada totalmente procedente por el STF, habiendo sido decretada la no recepción de la ley de imprenta (Ley No 5.250/1967). Ya la ADPF No 153 fue juzgada improcedente. La ADPF No 54 aún aguarda sentencia.

14 Artículo 1.723. "Es reconocida como entidad familiar la unión estable entre el hombre y la mujer, configurada en la convivencia pública, continua y duradera, y establecida con el objetivo de constitución de familia". 
titucional (Verfassungswandlung) que funcionaría, en verdad, como un verdadero proceso de modificación constitucional (Verfassungsänderung), reservado al espacio del Poder Constituyente derivado por la vía del proceso de enmienda constitucional.

El riesgo que surge de ese tipo de acción es que una intervención de esta monta del Poder Judicial en el seno de la sociedad produce graves efectos colaterales. Es decir: hay problemas que simplemente no pueden ser resueltos por la vía de una idea errónea de activismo judicial. El Poder Judicial no puede sustituir al legislador (no olvidemos, aquí, la diferencia entre activismo y judicialización: el primero, debilitador de la autonomía del derecho; el segundo, contingencial) ${ }^{15}$. Innecesario referir las innúmeras decisiones judiciales que obligan a los gobiernos a costear tratamientos médicos experimentales (incluso fuera de Brasil), suministro de medicamentos para erección masculina y tratamiento de la calvicie.

El verdadero caos procesal que se instaló en el caso del reconocimiento de las uniones homoafectivas da la muestra de cómo la discusión sobre el papel del Poder Judicial en el contexto de una democracia constitucional es algo que causa turbulencia en el Derecho Brasileño. Como está mencionado arriba, en la decisión que sanó el proceso, el entonces presidente de la Corte, Min. Gilmar Mendes, señaló, de forma correcta, que la ADPF no se presentaba como el mejor mecanismo para la solución de la demanda, pues no se vislumbraba cuál era la omisión del Estado y en qué grado se presentaba para el deslinde de la cuestión. Así, como consecuencia de esa necesidad de adecuación de la vía procesal, la ADPF 178 fue transformada en ADIn (Ação Direita de InconstitucionalidadeAcción Directa de Inconstitucionalidad) inscrita con el número de orden 4277. Para hacer aún más compleja la cuestión, incluso antes de la Procuraduría General de la República haber impetrado la ADPF No 178, el Gobernador del Estado de Rio de Janeiro ya había cuestionado la constitucionalidad de la "falta" (sic) de protección del Estado a las Uniones Homoafectivas en la ADPF No 132. Así, en mayo del 2011 el STF juzgó la ADPF No 132 y la ADIn 4277, la primera

15 Anótese que hay una fracción considerable de autores brasileños preocupados con los problemas oriundos de esa equivocada recepción de la idea de activismo judicial en Brasil. Podemos registrar, en este sentido, VAlLE, Vanice Regina Lírio do (org.) (2009): Ativismo Jurisprudencial e o Supremo Tribunal Federal. Laboratório de Análise Jurisprudencial do STF (Curitiba, Juruá). Además, es siempre conveniente recordar lo siguiente: mientras el activismo judicial está umbilicalmente asociado a un acto de voluntad del órgano judicante, la judicialización de cuestiones políticas o sociales no depende de ese acto volitivo del poder judicial, sino que deriva de la expansión de la sociedad (que se vuelve cada vez más compleja) y de la propia crisis de la democracia, que tiende a producir un número gigantesco de regulaciones (sea a través de leyes, medidas provisionales, decretos, etc.) y que encuentran su punto de capilarización en el judicial y, principalmente, en las cuestiones cuyo deslinde envuelve actos de jurisdicción constitucional. 
impetrada por el Gobernador del Estado de Rio de Janeiro y la segunda por la Procuraduría General de la República.

Las acciones fueron juzgadas parcialmente procedentes, habiendo el Tribunal, por unanimidad, reconocido la protección del Estado a las Uniones Homoafectivas, realizando una interpretación conforme a la Constitución del artículo 1.723 del Código Civil Brasileño. Los argumentos que compusieron la red discursiva presente en los votos son, en la gran mayoría, sociológicos y/o de moral. El enfrentamiento de la cuestión jurídica principal -o sea, de la legitimidad que la jurisdicción constitucional sustituyese al poder constituyente derivado, alterando el texto de la constitución - fue evitado por la mayoría de los ministros que se limitaron a afirmar que la idea de contención del Poder Judicial, en un caso como este, representaba una "visión oblicua" (sic) de las funciones del Poder Judicial en el derecho moderno, como señaló el Min. Marco Aurélio, en observación al voto del Min. Gilmar Mendes.

Sólo para ilustrar lo que aquí está siendo dicho, es importante consignar que, en el voto del relator, por ejemplo, está dicho que, "el órgano sexual es un plus, un bono, un regalo de la naturaleza. No es un peso, un estorbo, menos aún una reprimenda de los Dioses". En el voto de otro Ministro, se lee que, "la homosexualidad es rasgo de la personalidad, no es creencia, ideología u opción de vida"16. Por estos ejemplos, es posible visualizar que el juicio de estas acciones fue determinado, mucho más, por el entendimiento personal - de ahí la cuestión del solipsismo- de cada ministro con respecto a la materia, que por una interpretación técnica de la Constitución.

Además, podríamos ir adelante en la identificación clara del activismo de la corte en este caso: en uno de los votos, se llegó a decir que el reconocimiento de las Uniones Homoafectivas para efectos de la protección del Estado podría contribuir para la disminución de la discriminación y ayudaría a contener, incluso, prácticas violentas derivadas de la homofobia. Por cierto que la disminución de la discriminación es algo saludable, bien como debe ser repudiada cualquier tipo de acción violenta en contra de los homosexuales (al final, tal cual Norbert Elias, hay que creer en el "proceso civilizador"). Sin embargo, es de preguntarse si ese tipo de juicio -nítidamente político (y sin bases empíricas) - podría servir como fundamento de una decisión judicial.

\footnotetext{
16 Aquí cabe un comentario: ¿̨i fuese creencia, ideología u opción de vida, la protección del Estado debería ser rechazada? Pero, y ¿̨la libertad de expresión que también es garantía constitucional? Más aún ¿Cuál es la base científica en la que se apoya el argumento de que es la homosexualidad un "rasgo de la personalidad"? ¿Sería el Judicial la instancia correcta para afirmar eso como una constatación, cuyas discusiones en el ámbito de la psicología no son, ni de lejos, consensuales?
} 
De todos modos, el caso presentado, tanto en el origen como en su desenlace, representa muy bien cómo la discusión sobre el activismo interpretativo del Supremo Tribunal Federal se realiza en el campo jurídico brasileño.

Al lado de esas tres posturas -que se convirtieron en dominantes en el plano de la doctrina y de la aplicación del derecho en Brasil- pueden aun ser referidas manifestaciones calcadas en pragmatismos de los más variados, la mayoría de las veces construidos a partir de mezclas teóricas asistemáticas y contradictorias ${ }^{17}$. Puede afirmarse, aun, que, a veces, los pragmatismos toman prestados presupuestos originarios de las teorías argumentativas, en especial la de Alexy, principalmente cuando las decisiones judiciales aplican la proporcionalidad y la razonabilidad ${ }^{18}$.

\section{LA REACCIÓN DEL ESTABLISHMENT AL ACTIVISMO JUDICIAL,}

\section{AL PANPRINCIPIOLOGISMO Y LA FRAGMENTACIÓN JURISPRUDENCIAL}

Como puede percibirse, la así denominada "era de los principios", que propició el surgimiento de textos constitucionales con características sociales directivas encontró -principalmente en países como Brasil- un imaginario jurídico todavía muy dependiente de la metodología tradicional y de sus variaciones, a partir de un amplio espectro que abarcaba desde normativistas (formalistas) hasta adeptos del derecho alternativo (realistas al estilo de los Critical Legal Studies). En efecto, de un lado, doctrina y jurisprudencia, aún vinculadas a la dogmática jurídica tradicional, continuaron sosteniendo prácticas normativistas, con enormes dificultades para comprender mínimamente el surgimiento de una nueva teoría de las fuentes; ya de otro, sectores que, a pesar de comprometidos con la concretización de la Constitución, pasaron a apostar en el Poder Judicial como conductor de ese proceso, pero sin la correspondiente reflexión con relación a las condiciones de posibilidad de ese protagonismo.

O sea, la falta de teorías adecuadas a las demandas de una Constitución como la brasileña permitió la formación de un fuerte protagonismo judicial. Lo espantoso

17 Gran parte de la doctrina no obra a partir de presupuestos teóricos, sino de forma pragmaticista. No es difícil percibir la mezcla de procedimentalismo habermasiano con el modelo alexyano de ponderación. O sea, autores con tesis contradictorias entre sí sirven de fundamento para tesis y decisiones judiciales. En innúmeros casos, neoconstitucionalismo es confundido con una mera continuidad del positivismo normativista. Como consecuencia de eso: un caos interpretativo.

18 En este sentido, no es difícil percibir el modo por el que la ponderación, la razonabilidad y la proporcionalidad fueron siendo transformadas en enunciados de actuación. Sólo para ejemplificar: STF-RCL 2126; AGR 395662; TJRS 70027526524, 70027525898, 70032218398; STF-HC 97197; HC 97677; RMS 27920; ADPF 101; ADI 2240; STJ- HC 68397. 
es que, incluso frente a un texto constitucional riquísimo en derechos fundamentales sociales -experiencia única en el mundo- los intérpretes brasileños aun así vienen buscando descubrir "valores escondidos" debajo de esa tensa tesitura legal.

Una de las bases del activismo judicial y que provocó una fragmentación en la aplicación judicial fue el fenómeno del panprincipiologismo. "Se Positivaron los valores": así se suelen anunciar los principios constitucionales, circunstancia que facilita la "creación" (sic), en un segundo momento, de todo tipo de "principio" (sic), como si el paradigma del Estado Democrático de Derecho fuese la "piedra filosofal de la legitimidad principiológica”, de la que pudiesen ser extraídos tantos principios cuantos los necesarios para resolver los casos difíciles o "corregir" (sic) las incertidumbres del lenguaje. Cientos de principios invadieron el universo de la interpretación y aplicación del derecho, fragilizando mucho el grado de autonomía del derecho y la propia fuerza normativa de la Constitución, pudiendo ser enumerados, ejemplificadamente, algunos de ellos, tales como: principio de la simetría, el principio de la no sorpresa, principio de la confianza, principio de la afectividad, principio del hecho consumado, principio de la instrumentalidad procesal y el principio de la confianza en el juez de la causa.

Ese activismo demuestra también que su ratio posee un origen solipsista, lo que acaba siendo problemático, porque la democracia y los avances pasan a depender de las posiciones individuales de los jueces y de los Tribunales. De todos modos -y eso hay que dejarlo muy claro- solamente frente a la consagración de una efectiva jurisdicción constitucional es que puede hablarse sobre el problema de los activismos judiciales.

Por otro lado, hay que tener en cuenta que el constitucionalismo surgido de la segunda posguerra es, fundamentalmente, pospositivista; los textos constitucionales -ahora principiológicos-albergan esa nueva perspectiva del derecho. En este contexto, la búsqueda de la preservación de la fuerza normativa de la Constitución siempre corre el riesgo de quedar fragilizada por la equivocada apuesta en esa pretensa "apertura interpretativa", una vez que -y es en este punto que se da, en el campo filosófico, el pasaje del esquema sujeto-objeto a la relación sujeto-sujeto-, la abundante principiología vino para introducir, en el derecho, el mundo práctico que de él había sido excluido por las diversas posturas positivistas. Se entiende el positivismo ${ }^{19}$, para los límites de este análisis, a partir de su principal característica

19 Es importante resaltar que, para efectos de lo que trato en el texto, considero superado el positivismo exegético o legalista. Esto porque es posible decir que con Kelsen hay un cambio semántico en la interpretación del derecho: ya no hay una identidad isomórfica entre las palabras de la ley y la realidad factual. Para el 
señalada por Dworkin en su debate con Hart: la discrecionalidad, que ocurre a partir de la "delegación", en favor de los jueces, del poder de solucionar los casos difíciles. Es indubitable la relación de la discrecionalidad -delegada por Hart al juez- con el decisionismo kelseniano. Discrecionalidad será, así, el poder conferido al juez/intérprete para elegir una entre varias alternativas. El problema es saber si las alternativas son legítimas y si la "elección" se encuadra en la circunstancia discutida. Considérese, además, el problema de esa "delegación” en los casos de la interpretación del proceso judicial, que queda a merced de la interpretación discrecional del juez. El telón de fondo era -y aún lo es- la discusión sobre las condiciones de posibilidad de la realización de la democracia. Al final, si alguien tiene que decidir por último, la pregunta que surge obligatoriamente es: ¿̨de qué modo podemos evitar que la legislación -supuesto producto de la democracia representativa (producción democrática del derecho) - sea solapada por la falta de legitimidad de la jurisdicción?

Puede decirse que, tanto en la operacionalidad stricto sensu como en la doctrina, son perceptibles como mínimo dos tipos de manifestación del paradigma de la subjetividad, que envuelve exactamente las cuestiones relativas al activismo, decisionismo y la admisión del poder discrecional. El primero trata del problema de forma más explícita, "asumiendo" que el acto de juzgar es un acto de voluntad (para no olvidar el octavo capítulo de la Teoria Pura del Derecho de Kelsen) ${ }^{20}$; aun en este primer grupo deben ser incluidas las decisiones que, en su resultado, implícitamente tratan/trataron de la interpretación al modo solipsista. Son decisiones que se basan en un conjunto de métodos a veces incompatibles o incoherentes

positivismo de corte kelseniano la interpretación del derecho es un acto de voluntad que se desliza en el interior de una estructura abierta nominada metafóricamente como marco de la norma (Teoria Pura do Direito, Capítulo VIII). Es en este punto que se encuentra el espacio de discrecionalidad del intérprete aplicador de la norma y es para el enfrentamiento de esta dimensión que apunto mis armas.

20 Véase cómo esta cuestión del positivismo kelseniano no está superada en Brasil. En el STF, uno de los ministros más antiguos sostiene a menudo en sus posiciones que la interpretación es un acto de voluntad (en la línea de la afirmación kelseniana presente del Capítulo VIII de su Teoria Pura). En pronunciamiento reciente, el ministro afirmó que, aunque la decisión es un acto en partes, en el que la primera etapa representa la construcción "ideal" (sic) de la solución para el caso y, solamente en un segundo momento, es que se buscaría la justificación de lo decidido en el ordenamiento jurídico. En las palabras del Min. Marco Aurélio de Mello: "Idealizo para el caso concreto la solución más justa y posteriormente voy al armazón normativo, voy a la dogmática a buscar el apoyo. Y como la interpretación es principalmente un acto de voluntad, en la mayoría de las veces, encuentro el indispensable apoyo" (disponible en: http://www.stf.jus.br/portal/cms/ verNoticiaDetalhe.asp?idConteudo=154675. Acceso el: 6.07.2010); véase también: http://www.conjur.com. br/2010-jul-06/idealizo-solucao-justa-depois-vou-ar-normas-marco-aurelio.

Acceso el: 6.07.2010. 
entre sí o, aun, basadas en lecturas equivocadas de autores como Ronald Dworkin o incluso Hans-Georg Gadamer, confundiendo la "superación" de los métodos con una "libre atribución de sentidos".

De este modo, la defensa de posturas judiciales activistas, el crecimiento del panprincipiologismo y la fragmentación jurisprudencial, son fenómenos que derivan, en último análisis, de un mismo núcleo problemático: la preservación subterránea del paradigma de la filosofía de la consciencia en la construcción de las teorías y doctrinas del derecho. Un pragmatismo primitivo es invocado para justificar las decisiones individuales. Estas decisiones no conducen a un punto coherente, capaz de unificar el sentido y acomodarlo en un contexto de integridad. Así, un verdadero caos interpretativo acaba por tener lugar, algo que puede ser comparado al estado de naturaleza hobbesiano; una especie de Estado de naturaleza hermenéutico.

Pues bien, frente a ese duro proceso de fragmentación decisional, el establishment jurídico reaccionó creando mecanismos burocráticos que, supuestamente, pudiesen ofrecer una respuesta a ese enmarañado de decisiones y, a la vez, conducir a una racionalización del acceso a la justicia que, por fuerza de la ampliación constitucional de las demandas, también llevaba a un agotamiento del sistema. De este modo, la reforma llevada a cabo por la Enmienda Constitucional No 45/2004 (que quedó conocida como "Reforma del Judicial") creó dos mecanismos que venían por la senda de las cuestiones levantadas en ese tópico: las súmulas vinculantes ${ }^{21}$ y la repercusión general22.

21 Súmulas Vinculantes son enunciados creados por el STF siempre que haya decisiones reiteradas de la corte sobre una determinada materia puesta en juicio. La peculiaridad del sistema brasileño es que esos enunciados sumulares vinculan al propio STF, los tribunales inferiores y los órganos de la administración pública (cf. Artículo 103-A de la CF). Lo que causa perplejidad es que las súmulas no son ni exactamente precedentes (pues son enunciados generales y abstractos que se proponen resolver casos futuros; al paso que los precedentes de la common law son resueltos a partir de experiencias particulares con objetivo principal de solucionar el caso en disputa y sólo indirectamente repercuten en las decisiones futuras); pero tampoco es ley, una vez que emana del órgano de cúpula del Poder Judicial. Las Súmulas Vinculantes era una reivindicación antigua de una parcela significativa de los juristas brasileños. Las justificativas para adopción de dichos mecanismos siempre obedecían a un factor de orden pragmático: número excesivo de demandas repetitivas -cuya causa siempre es debitada a la constitución (Artículo $5^{\circ}$, inciso $35^{\circ}$ ) que amplió significativamente el acceso a la justicia y a la dificultad de controlar el sentido de las interpretaciones efectuadas por los jueces.

22 En la línea del problema envolviendo el exceso de procesos y del agotamiento del sistema a partir de la proliferación de recursos y medidas de revisión de las decisiones que están por ser juzgadas por los Tribunales, el mecanismo de la Repercusión General aparece como un obstáculo para la entrada de nuevos recursos que están por ser analizados y juzgados por el STF. En esta medida, los recursos extraordinarios aventados, solamente serán aceptados si pueden demostrar, en la tesis que fundamenta la demanda, la existencia de 
En suma, esos dos mecanismos son respuestas estructurales para un problema que es de orden paradigmático: de nada valen las súmulas y los demás mecanismos vinculatorios -como es el caso de la repercusión general- si no enfrentamos aquello que posibilitó todo cuadro de fragmentación, relativismo y subjetivismo que acomete el Derecho actual. O sea, es necesario superar la filosofía de la consciencia y aquel que es su creación: el sujeto solipsista (Selbstsüchtiger). El conocimiento -más que una relación que se da entre un sujeto y un objeto, es un encuentro. Un encuentro que ocurre a partir de un entorno, de una historia, en fin, de una tradición. Es de la explicitación de este encuentro que resultará la efectiva superación del artificialismo epistemológico de la filosofía de la consciencia que siempre lleva a soluciones despistadoras, que acaban llevando a la persistencia del núcleo del problema (en el caso brasileño, basta ver cómo la doctrina está tratando la cuestión de las súmulas: se piensa que los problemas de la interpretación de textos pueden ser resueltos con la edición de más textos, en una especie de eterno retorno a la Escuela de Exégesis). En una palabra: la superación de esos problemas es una tarea hermenéutica. Lo que voy a presentar a continuación es una propuesta para la realización de esa superación.

\section{LA RESPUESTA HERMENÉUTICA AL ACTIVISMO}

En contra del relativismo valorativo causado por la mala recepción de la jurisprudencia de los valores (a partir de la teoría de la argumentación de matriz alexyana) y en contra del activismo pragmatista de los tribunales -factores que, sumados, acaban por llevar al panprincipiologismo y a la fragmentación de la jurisprudencia- vengo proponiendo una hermenéutica fuertemente anti-relativista y anti-discrecional. Este modo de trabajar la hermenéutica pasa por la constatación de dos factores que posibilitan la superación del paradigma de la filosofía de la consciencia. Se trata, en verdad, de dos revoluciones copernicanas ocurridas en el siglo XX que modificaron radicalmente los caminos del Derecho y de la Filosofía. En el campo jurídico, la revolución copernicana del derecho público cambió el centro gravitacional del derecho: ya no son los códigos del derecho privado, sino las Constituciones las que ejercen, ahora, la función de capilarización del orden jurídico. Esa alteración radical trajo como consecuencia, también, una revolución metodológica: Los métodos tradicionales del derecho privado -permeados por la filosofía de la consciencia -no eran adecuados para manipular los nuevos

\footnotetext{
Repercusión General reconocida previamente por la corte. La repercusión general, por lo tanto, es un filtro para evitar que cualquier demanda llegue hasta la suprema corte de Brasil.
} 
textos constitucionales, concebidos para hacer valer un orden democrático que, para más allá de cualquier solipsismo, debería conducir a una esfera pública e intersubjetiva de legitimación de los actos de poder del Estado. Así, otra revolución -igualmente copernicana- entra en escena: se cuida de aquello que quedó conocido como viraje lingüístico (linguistic turn) que opera una redefinición del papel del lenguaje en el proceso de conocimiento y abre nuevos caminos para la discusión del método en el derecho.

En el camino de esa transformación operada por el giro lingüístico -que denomino de giro lingüístico-ontológico (viraje ontológico-lingüístico)_23 aparece la hermenéutica de Hans-Georg Gadamer. A partir de Wahrheit und Methode quedó claro que la verdad de las ciencias humanas, o ciencias del espíritu, es un acontecimiento que puede ser percibido a través del arte, de la historia y del lenguaje. Gadamer lanza, así, un golpe certero contra el metodologismo que predominaba de la epistemología de esas ciencias afirmando que la verdad es algo que, en último análisis, se opone al método. En efecto, en vez de garantizar la objetividad de la interpretación, el método -en cuanto momento supremo de la subjetividad-acaba por llevar a relativismos (v.g. en el derecho la cuestión de la ponderación, por ejemplo).

Por ello, pienso que esa objeción gadameriana al relativismo metodológico encuentra eco en la crítica que Ronald Dworkin hace al poder discrecional de los jueces, que se muestra de manera emblemática en el debate llevado a cabo con Herbert Hart. Así, mi propuesta se presenta a partir de una imbricación entre Gadamer y Dworkin. En la senda de Dworkin, que, a su modo, hablará de la única respuesta correcta, propongo la tesis de que todo ciudadano -que vive bajo el manto del Estado Democrático de Derecho- tiene un derecho fundamental de obtener de los tribunales una respuesta constitucionalmente adecuada.

Mi propuesta, sin embargo, no establece ningún procedimiento metodológico que garantice esa respuesta adecuada. Al contrario, rechaza cualquier tipo de procedimentalización del proyecto decisorio. Para discutir las condiciones bajo las cuales se basa la respuesta constitucionalmente adecuada, necesitamos disponer antes de una teoría de la decisión. Dicha teoría de la decisión necesita conseguir destilar los equívocos advenidos de las erróneas importaciones teóricas efectuadas por el constitucionalismo brasileño y debe conseguir producir un riguroso proceso de justificación de las decisiones que circulan entre la suspensión de los prejuicios del intérprete (en el sentido hermenéutico que debe ser entendido de

23 En este sentido, véase STRECK, Lenio Luiz (2013). 
la siguiente forma: quien decide sobre cuestiones político-jurídicas tiene el deber de aclarar previamente los conceptos con los que está operando en el momento de la decisión), las circunstancias que componen el caso concreto y la recomposición coherente de la historia institucional del derecho (que comporta una legislación, una jurisprudencia y una doctrina).

En esta medida, como los procedimientos y metodologías son rechazados por orden judicial provisional, el único modo de demostrar la validez de la tesis se da a partir de la reconstrucción de un caso concreto, en el que se puede percibir la manifestación de la respuesta constitucionalmente adecuada.

\section{La hermenéutica y los Principios conformadores de la aplicación del derecho en el Estado Democrático de Derecho}

Una nueva perspectiva hermenéutica, por lo tanto, viene forjándose en el seno de la doctrina brasileña ${ }^{24}$, a partir de dos rupturas paradigmáticas: la revolución del constitucionalismo, que institucionaliza un elevado grado de autonomía del derecho, y la revolución provocada por el giro lingüístico-ontológico. De un lado, la existencia de la Constitución exige la definición de los deberes sustanciales de los poderes públicos que van más allá del constitucionalismo liberal-iluminista, disminuyendo el grado de discrecionalidad del Poder Legislativo, así como del Poder Judicial en los denominados "casos difíciles". De otro, parece no quedar duda de que, contemporáneamente, a partir de los avances de la teoría del derecho, es posible decir que no existen respuestas a priori sobre el sentido de determinada ley que emanan de procedimientos o métodos de interpretación. En este sentido, "conceptos" que tengan la pretensión de abarcar, de antemano, todas las hipótesis de aplicación, nada más hacen que reducir la interpretación a un proceso analítico, que se caracteriza por el empleo "sistemático" del análisis lógico del lenguaje, buscando hallar el significado de los vocablos y de los enunciados, convirtiéndola en rehén de aquello que Dworkin llama de "aguijón semántico".

No percibimos, de forma distinta (escindida), primero los textos para, después, acoplarles sentidos. O sea, en la medida en que el acto de interpretar -que es siempre comprensivo/aplicativo- es unitario, el texto (pensemos, fundamentalmente, en la Constitución) no está, y no nos aparece, desnudo, como si estuviese a nuestra disposición. Con esto también desaparece cualquier diferenciación entre estructura y contenido normativo. De este modo, no podemos olvidarnos de que

24 Las propuestas aquí presentadas pueden ser consultadas, más detalladamente, en las siguientes obras: Streck, (2013a) y (2012); Tomaz de Oliveira, Rafael (1994); y Ramires, Mauricio (2010). 
mostrar la hermenéutica como producto de un raciocinio hecho por etapas, fue el modo que las diversas formas de subjetivismo encontraron para buscar el control político-ideológico del "proceso" de interpretación. De ahí la importancia conferida al método, que siempre tuvo/tiene la función de "aislar" la norma (sentido del texto) de su concretización.

Es importante señalar, además, que, a la diferencia de la comprensión de otros fenómenos, la hermenéutica jurídica contiene una especificidad: la de que el proceso hermenéutico posee un vector de sentido, producto de un proceso constituyente que no puede ser alterado a no ser por reglamento propio constante en el propio proceso originario. Y esto hace la diferencia. La Constitución es el eslabón material que une la política y el derecho, de donde puede decirse que el gran salto paradigmático en este periodo de la historia está exactamente en el hecho de que el derecho debe servir como garantía de la democracia.

Así, en la medida en que estamos de acuerdo que la Constitución posee características especiales oriundas de un profundo cambio paradigmático, el papel de la hermenéutica pasa a ser, fundamentalmente, el de preservar la fuerza normativa de la Constitución y el grado de autonomía del derecho frente a las tentativas usurpadoras provenientes del proceso político (comprendido lato sensu). En este contexto, la gran ingeniaría a ser hecha es, de un lado, preservar la fuerza normativa de la Constitución y, de otro, no poner la política a remolque del derecho.

Esta (inter)mediación es el papel a ser desempeñado por los principios forjados en la tradición del Estado Democrático de Derecho. Los principios funcionan, así, como Leitmotiv del proceso interpretativo, mostrando que cada enunciado jurídico posee una motivación (Jede Aussage ist motiviert, dirá Gadamer). Principios tienen la función de mostrar/denunciar la ruptura con la plenipotenciaridad de las reglas; el derecho no exime al intérprete de cualquier compromiso con la realidad.

Por tales razones, es fundamental que se pase a entender que "metodología" o "principiología" constitucional no quieren significar "cánones", "reglas" o "metareglas", sino un modo de concretar la Constitución, es decir, el modo por el que la Constitución debe ser "efectivamente interpretada".

De este modo, se propone, aquí, un conjunto mínimo de principios (hermenéuticos) para que sean seguidos por el intérprete. Dichos principios, sostenidos en la historicidad de la comprensión y en la sedimentación de esa principiología, solamente se manifiestan cuando son puestos en un ámbito de reflexión que es radicalmente práctico-concreto, pues representan un contexto de significaciones históricas compartidas por una determinada comunidad política. La interpretación del derecho solamente tiene sentido si implica un riguroso control de las decisiones judiciales, porque se trata, fundamentalmente, de una cuestión que llega al núcleo de ese nuevo paradigma: la democracia. Y sobre esto parece no haber desacuerdo. 


\section{Principio uno: \\ la preservación de la autonomía del derecho}

Este principio interpretativo abarca varios patrones compartidos por el derecho constitucional a partir de la segunda posguerra, denominados de métodos o principios, tales como el de la corrección funcional (designado por Müller como principio autónomo que veda la alteración, por la instancia decisoria, de la distribución constitucionalmente normatizada de las funciones ni por intermedio de su resultado), el de la rigidez del texto constitucional (que blinda el derecho contra las convicciones revolucionarias acerca de la infalibilidad del legislador), el de la fuerza normativa de la Constitución y el de la máxima efectividad (sentido que le de a la Constitución la mayor eficacia, como sostienen, por todos, Pérez Luño y Gomes Canotilho). Más que apoyatura del Estado Democrático, la preservación del acentuado grado de autonomía conquistado por el derecho es su propia condición de posibilidad y por ello es erigido, aquí, a la condición de principio basilar, uniendo la visión interna y la visión externa del derecho. Se trata, también, de una "garantía contra el poder contramayoritario", abarcando la garantía de la legalidad en la jurisdicción.

En ese nuevo paradigma, el derecho debe ser comprendido en el contexto de una creciente autonomización, alcanzada ante los fracasos de la falta de control de la y sobre la política. La Constitución es, así, la manifestación de este (acentuado) grado de autonomía del derecho, debiendo entenderlo en su dimensión autónoma frente a otras dimensiones con él intercambiables, como, por ejemplo, la política, la economía y la moral (y aquí hay que tener especial atención, una vez que la moral ha sido utilizada como la "puerta de entrada" de los discursos adjudicadores con pretensiones correctivas del derecho, trayendo consigo la política y el análisis económico del derecho; es en este contexto en el que debe ser vista la "retomada" de la moral por el derecho, a partir de aquello que Habermas tan bien denomina de co-originariedad). Esa autonomización se da en el contexto histórico del siglo $\mathrm{XX}$, habiendo alcanzado su auge con la elaboración de las Constituciones de la segunda posguerra.

\section{Principio dos: el control hermenéutico de la interpretación constitucional - la superación de la discrecionalidad}

A partir del "acortamiento" del espacio de maniobra y conformación del legislador y del consecuente aumento de la protección contra mayorías (eventuales o no) -núcleo del contramayoritarismo-, parece evidente que, para la preservación 
del nivel de autonomía conquistado por el derecho, es absolutamente necesario implementar mecanismos de control de aquello que es el repositorio del desplazamiento del polo de tensión de la legislación a la jurisdicción: las decisiones judiciales. En otras palabras, la autonomía del derecho y su umbilical conexión con la dicotomía "democracia-constitucionalismo" exigen de la teoría constitucional una reflexión de cuño hermenéutico.

Es importante referir, además, que la defensa de un efectivo control hermenéutico de las decisiones judiciales, a partir del deber fundamental de justificación y del respeto a la autonomía del derecho, no quiere decir que, a veces, no sea aconsejable y necesaria una actuación propositiva del Poder Judicial (justicia constitucional), principalmente si pensamos en el indispensable control de constitucionalidad que debe ser hecho incluso, en el límite, en las políticas públicas. Sin embargo, la defensa de posturas sustancialistas y concretistas acerca de la utilización de la jurisdicción constitucional -que implica inexorable avance con relación a las tradicionales posturas self restraining - no puede ser confundida con decisionismos y actitudes pragmatistas, en el que el Poder Judicial sustituye al legislador, con el aumento desmesurado de protagonismos judiciales. Es decir, se debe evitar aquello que se denomina "activismo".

\section{Principio tres: el respeto a la integridad y a la coherencia del derecho}

Como forma de establecer barreras contra la fragmentación propia de las teorías pragmatistas en general, el respeto a la integridad y a la coherencia engloba principios (que, a veces, se confunden con "métodos" de interpretación) construidos a lo largo de los años por la teoría constitucional, tales como el principio de la unidad de la Constitución, el principio de la concordancia práctica entre las normas o de la armonización, el principio de la eficacia integradora o del efecto integrador, e incluso el principio de la proporcionalidad (aunque su uso sin criterio). Su funcionalidad depende de otra garantía constitucional: la de la necesidad de la fundamentación de las decisiones (artículo 93, X, de la CRFB), aquí alzada a deber fundamental del juez y a derecho fundamental del ciudadano.

La integridad está umbilicalmente conectada a la democracia, exigiendo que los jueces construyan sus argumentos de forma integrada al conjunto del derecho ${ }^{25}$. Se trata, pues, de "consistencia articulada". Con esto, se aleja, de pronto, tanto

25 Dworkin, (1986), p. 176. 
el punto de vista objetivista, por el cual "el texto carga consigo su propia norma" (ley es ley en sí), como el punto de vista subjetivista-pragmatista, para el cual la norma puede hacer zozobrar el texto. O sea, ese respeto a la tradición, ínsito a la integridad y a la coherencia, es sustancialmente anti-relativista y debe servir de blindaje contra subjetivismos y objetivismos.

\section{Principio cuatro:} el deber fundamental de justificar las decisiones

Si nos ponemos de acuerdo en que la hermenéutica a ser practicada en el Estado Democrático de Derecho no puede deslegitimar el texto jurídicoconstitucional producido democráticamente, parece evidente que hay una fuerte responsabilidad política de los jueces y tribunales, circunstancia que fue albergada en el texto de la Constitución, en la especificidad del artículo 93, IX, que determina, aunque con otras palabras, que el juez explicite las condiciones por las cuales comprendió.

El deber de fundamentar las decisiones (y no solamente la decisión final, pero todas las del iter) está asentado sobre un nuevo nivel de participación de las partes en el proceso decisorio. La fundamentación está vinculada al control de las decisiones, y el control depende de esa alteración paradigmática en el papel de las partes de la relación jurídico-procesal. Por ello, el protagonismo judicialprocesal debe zozobrar ante una adecuada garantía a lo contradictorio y ante los principios ya delineados. Decisiones de carácter "cognitivista", de oficio o que, tardíamente, aún buscan la "verdad real", se pretenden "inmunes" al control intersubjetivo y, por dichas razones, son incompatibles con el paradigma del Estado Democrático. El Supremo Tribunal Federal de Brasil (MS 24.268/04, Rel. Min. Gilmar Mendes) da señales cíclicas de la incorporación de esa democratización del proceso, haciéndolo con base en la jurisprudencia del Tribunal Constitucional Federal de Alemania (Bundesverfassungsgericht), es decir, la pretensión a la tutela jurídica corresponde a la garantía consagrada en el artículo $5^{\circ}, \mathrm{LV}$, de la CF, conteniendo los siguientes derechos: (a) derecho de información (Recht auf Information), que obliga al órgano juzgador a informar a la parte contraria de los actos practicados en el proceso y sobre los elementos de él constantes; (b) derecho de manifestación (Recht auf Äusserung), que asegura al defensor la posibilidad de manifestarse oralmente o por escrito sobre los elementos fácticos y jurídicos que constan del proceso; (c) derecho de ver sus argumentos considerados (Recht auf Berücksichtigung), que exige del juez capacidad, aprensión y exención de ánimo 
(Aufnahmefähigkeit und Aufnahmebereitschaft) para contemplar las razones presentadas. El mismo acórdão de la Suprema Corte brasileña incorpora la doctrina de Dürig/Assmann, sosteniendo que el deber de conferir atención al derecho de las partes no sólo implican la obligación de tomar conocimiento (Kenntnisnahmeplicht), sino que también la de considerar, seria y detenidamente, las razones presentadas (Erwägungsplicht).

\section{Principio cinco: \\ el derecho fundamental a una respuesta constitucionalmente adecuada}

Este principio tiene una relación de estricta dependencia del deber fundamental de justificar las decisiones y de aquellos principios (o subprincipios) -acuñados por la tradición constitucionalista- que tratan del efecto integrador (vinculado al principio de la unidad de la Constitución), de la concordancia práctica o de la armonización, de la máxima efectividad y de la interpretación conforme la Constitución. Como principio instituidor de la relación jurisdicción-democracia, la obligación de fundamentar-que, importante citar, no es una fundamentación de carácter apodíctico- tiene como objetivo preservar la fuerza normativa de la Constitución y el carácter deontológico de los principios. Consecuentemente, representa un blindaje contra interpretaciones deslegitimadoras del contenido que sostiene el dominio normativo de los textos constitucionales. Se trata de sustituir cualquier pretensión solipsista por las condiciones histórico-concretas, siempre recordando, en este contexto, la cuestión de la tradición, de la coherencia y de la integridad, para bien poder insertar la problemática en la superación del esquema sujeto-objeto por la hermenéutica jurídica.

Hay un derecho fundamental al cumplimiento de la Constitución. Más que eso, se trata de un derecho fundamental a una respuesta adecuada a la Constitución o, si así se quiere, una respuesta constitucionalmente adecuada (o, aun, una respuesta hermenéuticamente correcta con relación a la Constitución). Antes de cualquier otro análisis, se debe siempre buscar la compatibilidad constitucional de la norma jurídica con la Constitución y la existencia de eventual contradicción. Siempre debe preguntarse si, a la luz de los principios y de los preceptos constitucionales, la norma es aplicable al caso. Es más, hay que indagar en qué sentido señala la precomprensión (Vor-verständnis), condición para la comprensión del fenómeno. Para interpretar, es necesario comprender (verstehen) qué se quiere interpretar. Este "estar ante" algo (ver-stehen) es condición de posibilidad del obrar de los juristas: la Constitución. 
El derecho fundamental a una respuesta constitucionalmente adecuada no implica la elaboración sistémica de respuestas definitivas. Esto porque la pretensión de buscarse respuestas definitivas es, ella misma, anti-hermenéutica, frente al congelamiento de sentidos que esto propiciaría.

El derecho fundamental a una respuesta adecuada a la Constitución, más que un asentamiento de una perspectiva democrática (por lo tanto, de tratamiento ecuánime, con respecto a lo contradictorio y a la producción democrática legislativa), es un "producto" filosófico, porque es la base de un nuevo paradigma que supera el esquema sujeto-objeto predominante en las dos metafísicas (clásica y moderna).

\section{REFERENCIAS}

Austin, John L.: Cómo hacer cosas con palabras. Buenos Aires, Paidós, 1998.

Dahl, Robert A. (2009): "Tomada de Decisões em uma democracia: a Suprema Corte como uma entidade formuladora de políticas nacionais". En Revista de Direito Administrativo (No 252), pp. 25-43.

Dworkin, Ronald (1986): Law's Empire (Cambridge, Harvard University Press). HABERMAS, Jürgen (1992): Faktizität und Geltung. Beiträge zur Diskurstheorie des Rechts und des demokratischen Rechtsstaats. (Frankfurt am Main, Suhrkamp).

HiRsCHL, Ran (2007): Towards juristocracy: the origins and consequences of the new constitutionalism. (Cambridge, Harvard University Press).

(2009): "O novo constitucionalismo e a judicialização da política pura no mundo". En Revista de Direito Administrativo (No 251), pp. 139-178.

Ramires, Mauricio (2010): Critica à Aplicação de Precedentes no Direito Brasileiro. (Porto Alegre, Livraria do Advogado).

Shapiro, Martin; SWEet, Alec Stone (2002): On law, politics \& judicialization (New York, Oxford University Press).

STreck, Lenio Luiz (2013): Hermenêutica Jurídica em Crise. Décima primeira edição (Porto Alegre, Livraria do Advogado,).

(2013a): O que é isto - decido conforme minha consciência? Quarta edição (Porto Alegre, Livraria do Advogado).

(2012): Verdade e Consenso. Quarta edição (Rio de Janeiro, Lumen júris).

TAte, Chester Neal; vallinder, Torbjörn (1995): “The global expansion of Judicial Power: the judicialization of politics" en The global expansion of Judicial Power. (New Cork, New York University Press). 
Tomaz de Oliveira, Rafael (1994): Decisão Judicial e o Conceito de Principio. A hermenêutica e a (in)determinação do Direito en (Porto Alegre, Livraria do Advogado).

Valle, Vanice Regina Lírio do (org.) (2009): Ativismo Jurisprudencial e o Supremo Tribunal Federal. Laboratório de Análise Jurisprudencial do STF (Curitiba, Juruá).

Wolfe, Christopher (1994): The rise of modern Judicial Review. From constitutional interpretation to jugde-made law (Nova Cork, Rowman \& Littefieleld). 